\title{
Profitability of Adopting Extended Low Intensity Harvesting Systems for Rubber
}

\author{
Kudaligama K.V.V.S. ${ }^{{ }^{*}}$, Rodrigo V.H.L. ${ }^{1}$, Fernando K.M.E.P. ${ }^{2}$ and Yapa P.A.J \\ ${ }^{1}$ Rubber Research Institute, Agalawatta, Sri Lanka \\ ${ }^{2}$ Department of Botany, Faculty of Applied Sceiences, University of Sri Jayewardenepura, \\ Nugegoda, Sri Lanka \\ *vskudaligama@yahoo.com
}

\begin{abstract}
In harvesting, rubber tree is generally tapped along the half of the circumference of the trunk with the frequency of once in two days $(\mathrm{S} / 2 \mathrm{~d} 2)$. Low intensity harvesting (LIH) systems in rubber plantations appeared to be a practical solution to address the issues related to labour, high rate of bark consumption and cost of production. Low intensity of harvesting could be achieved by reducing either the frequency of harvesting or tapping cut length or both. Recently two extended low intensity systems i.e. S/2 d4 (tapped along the half of the circumference of the trunk with once in four days frequency) and S/4 d3 (tapped along the quarter of the circumference of the trunk with once in three days frequency) was recommended for harvesting rubber in Sri Lanka. Generally no estate would adopt LIH systems in its full extent. Therefore, profitability of adopting S/2 d4 and S/4 d3 systems in an estate with 500 ha at different rates was worked out for general information. In this case, effects on production cost, net income and harvester requirement were analysed with different adoption rates.
\end{abstract}

Adoption of $\mathrm{S} / 2 \mathrm{~d} 4$ and $\mathrm{S} / 4 \mathrm{~d} 3$ systems may reduce the total production cost at rates of 1.86 and 1.73 million rupees per $10 \%$ increase in adoption extent with $\mathrm{S} / 2 \mathrm{~d} 4$ and $\mathrm{S} / 3 \mathrm{~d} 4$ system, respectively However, adoption of the total extent of a 500 ha estate will get the benefit of reduction of the production cost in Rs.18.69 and 17.28 million annually compared to tapping the total extent with $\mathrm{S} / 2 \mathrm{~d} 2$ system.

Net annual income gained from 500 ha of rubber harvested with $\mathrm{S} / 2 \mathrm{~d} 2$ system will be Rs. $95.57 \mathrm{Mn}$. Adoption in $10 \%$ of the extent with $\mathrm{S} / 2 \mathrm{~d} 4$ and $\mathrm{S} / 4 \mathrm{~d} 3$ harvesting systems may increase the net income of the estate in Rs.1.87 Mn and 1.73 Mn per year, respectively. Adoption of $100 \%$ of the area with S/2 d4 and S/4 d3 system may increase the annual net income to Rs. 114.26 Mn and Rs. 112.85 Mn, respectively.

Harvesting 500ha of mature extent with 400 tappable trees needs 333 harvesters per day at $\mathrm{d} 2$ frequency. Adoption of $10 \%$ of the extent with $\mathrm{d} 4$ and $\mathrm{d} 3$ frequency may reduce the harvester requirement in $5 \%$ and $3 \%$, respectively. However, adoption of $100 \%$ of this extent with S/2 $\mathrm{d} 4$ and S/4 d3 harvesting systems reduces the daily required number of harvesters to 167 and 222 , respectively.

Keywords: Hevea, Low intensity harvesting 